\title{
CORPUS Corpus
}

Archivos virtuales de la alteridad americana

Vol. 10, No. 1 | 2020

Enero / Junio 2020

\section{El Museo de la Morgue Judicial: historias de guardianes, expedientes y apropiaciones}

\section{María José Sarrabayrouse Oliveira}

\section{(2) OpenEdition \\ Journals}

Electronic version

URL: http://journals.openedition.org/corpusarchivos/3451

DOI: $10.4000 /$ corpusarchivos.3451

ISSN: $1853-8037$

\section{Publisher}

Diego Escolar

\section{Electronic reference}

María José Sarrabayrouse Oliveira, «El Museo de la Morgue Judicial: historias de guardianes, expedientes y apropiaciones », Corpus [En línea], Vol. 10, №. 1 | 2020, Publicado el 28 junio 2020, consultado el 02 julio 2020. URL : http://journals.openedition.org/corpusarchivos/3451 ; DOI : https:// doi.org/10.4000/corpusarchivos.3451

This text was automatically generated on 2 July 2020 . 


\title{
El Museo de la Morgue Judicial: historias de guardianes, expedientes y apropiaciones
}

\author{
María José Sarrabayrouse Oliveira
}

\section{La llegada al Museo Forense}

1 Corría el año 2004 y me encontraba en pleno trabajo de campo para hacer mi tesis de doctorado en antropología sobre el funcionamiento del Poder Judicial durante la última dictadura militar en la Argentina. Para llevarlo a cabo había decidido realizar un extenso recorrido por un expediente judicial conocido en el mundillo de los tribunales como la "Causa de la Morgue Judicial".

2 Hasta ese momento había entrevistado a abogados, ex-funcionarios judiciales, familiares de víctimas de la dictadura, pero no había podido acceder a ningún médico de la Morgue; ni siquiera había logrado ingresar en ella. A pesar de conocer los obstáculos, vericuetos y hermetismo que caracterizan a las burocracias penales, el ingreso se estaba haciendo particularmente complicado y es así que resolví tener un acercamiento alternativo a través de lo que, entendía, constituía un espacio público y, por lo tanto, de más fácil acceso: el Museo de la Morgue Judicial.

3 Concerté una entrevista telefónica y, junto con una colega y amiga, nos presentamos en Junín 762 donde se emplaza el Museo Forense de la Justicia Nacional "Dr. Juan Bautista Bafico", en honor a uno de los directores de la Morgue Judicial, ubicado en lo que fuera, hasta principios del siglo XX, el Aula Magna de la Facultad de Medicina.

4 La historia que contaré a continuación ocurrió hace quince años. Nunca escribí sobre ella más que las anotaciones de rigor en mi libreta de campo. Guardé los registros, la documentación y algunos apuntes de unas charlas que mantuve fuera del Museo. La invitación para realizar este trabajo me "obligó" a desempolvar esa documentación archivada para retomar parte de las cuestiones que pude pensar en ese momento e incorporar otras que hoy veo a la luz de años de investigación sobre el campo. 


\section{De restos mortales, bisabuelos y expedientes}

Ingresamos al edificio de la Morgue Judicial y desde allí nos dirigimos al Museo: una única sala circular con altas ventanas y vitrinas iluminadas, las cuales contienen frascos donde es posible distinguir diferentes tejidos anatómicos sumergidos en conservantes químicos: cabezas, brazos, fetos, trozos de piel con tatuajes "tumberos" y hasta una momia andina, cuyo asilo en el Museo resultó un tanto inexplicable. Debo reconocer que ninguno de estos restos mortales me produjo particular impresión; sí fascinación. Tal vez la costumbre que teníamos con mis hermanos, cuando éramos niños, de mirar a escondidas los dos tomos de medicina forense de Bonnet anestesió mi impresión, a la vez que la clandestinidad del acto acicateó mi fascinación.

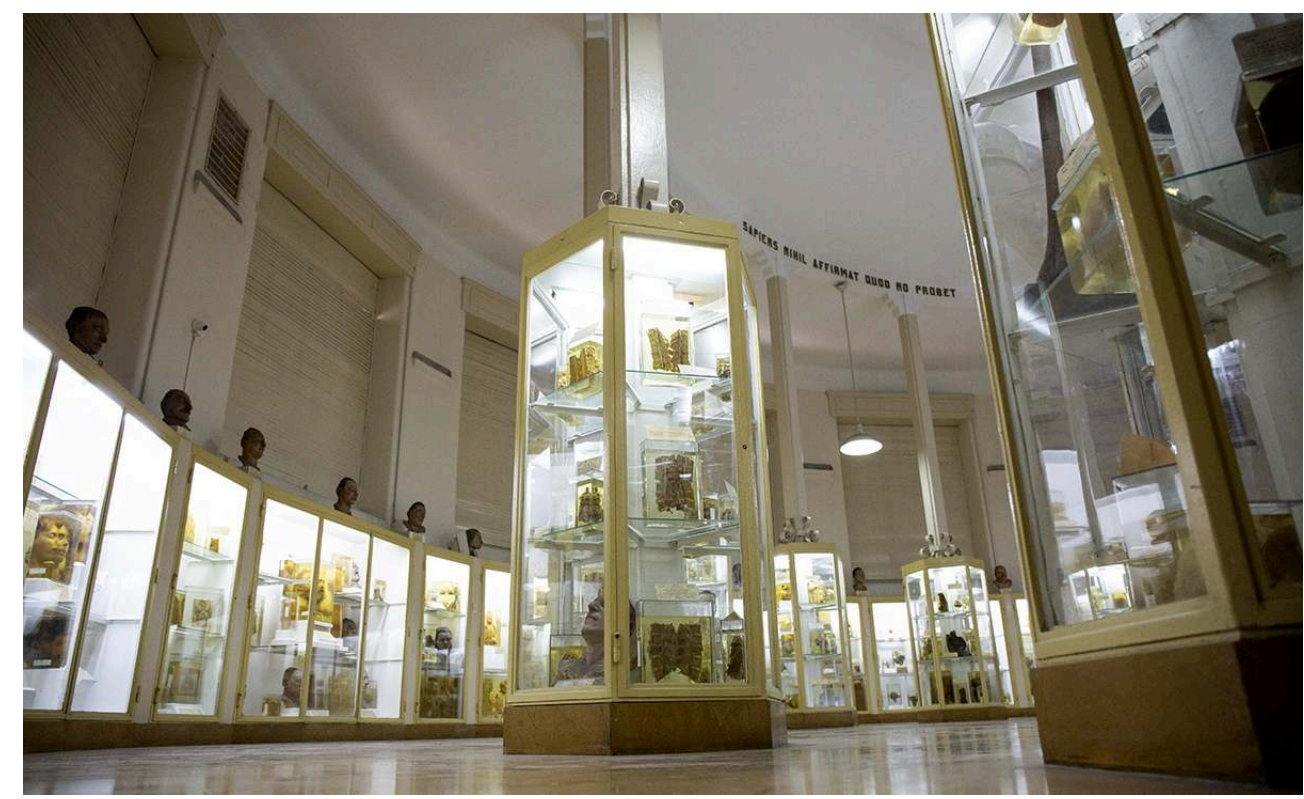

Imagen 1: Fotografía extraída de: https://www.cij.gov.ar/nota-33457-Museo-Forense--un-espacio-deinter-s-jur-dico-y-cient-fico.html\#showfotos

6 Las piezas anatómicas y sus fichas, aclarando características y circunstancias de la muerte, se llevaban toda nuestra atención. Sin embargo, transcurrido un tiempo y habiendo desfilado ya varias veces por las vitrinas, comencé a mirar hacia arriba de ellas; fue así que encontré unos bustos de yeso que las coronaban. Frente a los restos humanos conservados en frascos, y seguramente por un dejo de fascinación morbosa de mi parte, poco llamaban la atención estos bustos cuyos rostros eran máscaras mortuorias y estaban acompañados por unos pequeños cartones donde no figuraba el nombre del difunto pero sí su nacionalidad, año de muerte y oficio. A pesar del escaso interés inicial, comencé a mirar esas mascarillas de hombres -en su totalidad-, con bigotes -en su amplia mayoría- y que respondían en sus rasgos, sin mayores diferencias, al estereotipo del inmigrante de principios del siglo XX. Repentinamente, una imagen me resultó familiar. Me detuve. Miré con atención. Miré otros bustos. Volví al que me había llamado la atención. Era imposible. Leí varias veces la tarjetita explicativa para convencerme: español, 1938, panadero. Yo conocía esa cara. La había visto durante toda mi infancia en una foto de época, colgada en una pared de la casa de mis abuelos maternos... 
7 Con palpitaciones en el pecho, me dirigí a mi amiga y le conté que había encontrado a mi bisabuelo Oliveira, el panadero, el anarquista.

Presas del asombro y la ansiedad, nos dirigimos al encargado de la visita guiada y esperamos que terminase de brindar una explicación a unos estudiantes de derecho. Lo llevé a un apartado y le conté lo sucedido. Le mostré el busto y me dijo que aguardara unos minutos, que iba llamar a alguien que me podría confirmar si la máscara mortuoria que estaba allí, efectivamente, pertenecía a mi bisabuelo.

9 A los cinco minutos ingresó a la sala un hombre que, agitado e inquieto, comenzó a preguntar, con un tono elevado de voz, quién era la chica que había encontrado a su bisabuelo. Junto con mi amiga nos acercamos, le contamos todo nuevamente y, tomando la ficha descriptiva, nos dijo que iba a buscar el expediente de mi "supuesto" bisabuelo, aclarándonos que si estaba la figura en yeso también debía estar el legajo judicial. En ese momento recordé una suerte de máxima que funcionaba como estrella guía en mi investigación y me permitía entender el funcionamiento de las burocracias penales y lo que sucede con los cuerpos que ingresan a la morgue: si el cadáver ingresó, el registro burocrático de ese ingreso tiene que estar.

10 Acto seguido, el celoso guardián de los expedientes de la Morgue me pidió que lo acompañara a buscar a mi bisabuelo. Atravesamos la Morgue Judicial, un olor muy particular invadía el aire del edificio, mezcla de químicos y carne en descomposición.

11 Subimos unas escaleras y llegamos a una suerte de pasillo con pilas y pilas de expedientes atados y apoyados en el piso sin ningún orden aparente. "-En alguno de todos estos tiene que estar...”. Me señaló cerca de 30 o 40 paquetes - realmente no recuerdo cuántos, pero sí la sensación de empresa infinita- y me dijo que comenzáramos a revisar. Dispuesta a pasar una gran cantidad de horas en la Morgue, desaté el primer paquete. Los datos de las carátulas eran escuetos: nombre del cadáver, $\mathrm{n}^{\mathrm{o}}$ de orden, juez interviniente, comisaría y año, coronados por una imagen del escudo nacional seguido por la inscripción Morgue Judicial. Museo Forense, impresa en medio punto. Seguí revisando los expedientes y al llegar al décimo legajo, aproximadamente, no pude salir de mi estupor: en la línea correspondiente al nombre se leía "Oliveira, José". 


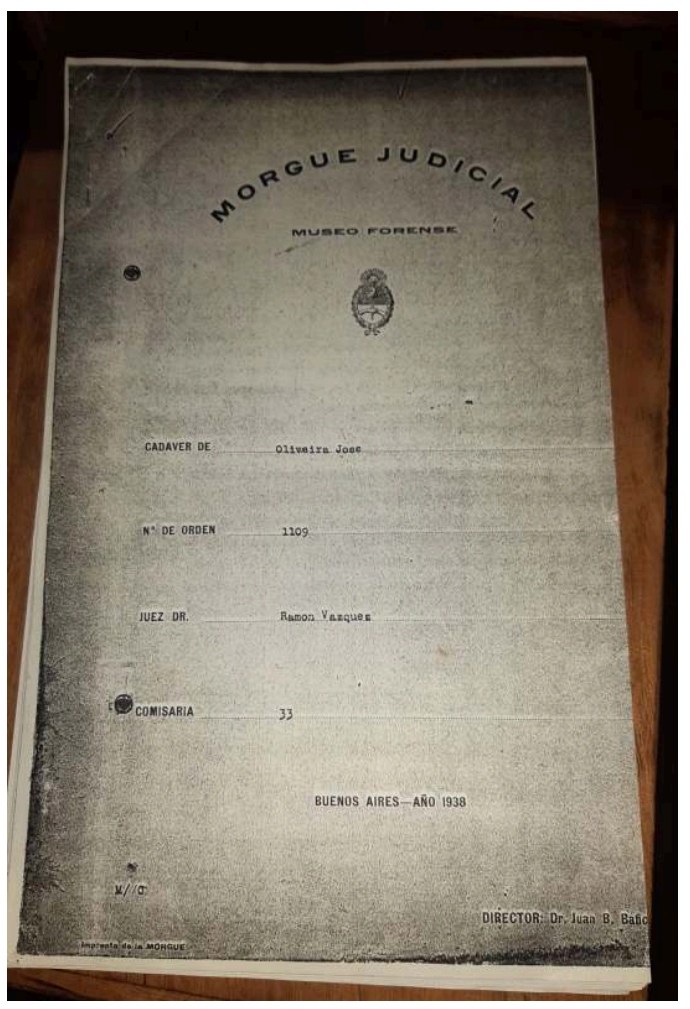

Imagen 2: Fotografía archivo personal de la autora.

12 Mi alegría y emoción fue tan grande como la del celoso guardián de los expedientes. No lo podíamos creer. De repente, ese lugar plagado de documentos de personas muertas por las que nadie reclamaba y que muy pocos investigadores consultaban, había cobrado vida.

13 Comencé a leer el expediente de solo quince páginas donde figuraba el nombre de mi bisabuelo, pero también los de mi abuelo y mi tío abuelo encargados de hacer los trámites correspondientes. Entre los distintos escritos se encontraba la remisión del cuerpo a la Morgue Judicial por orden del juez de instrucción interviniente, con la descripción de lo que hasta ese momento era el cuerpo de un hombre no identificado (NN) que vestía:

Camiseta frisa, saco de lana de relámpago, pantalón, calzoncillos, medias, zapatillas, cinturón y sombrero. Objetos: echarpe. Observaciones: estas ropas están en regular estado de conservación.

14 Acto seguido, en una nota del 13 de septiembre de 1938, el comisario de la sección 33 solicitaba al director de la Morgue, Juan Bafico,

Por disposición del señor Juez de Instrucción Dr. Ramón F. Vázquez (...) hacer entrega al agente portador del cadáver de JOSÉ OLIVEIRA, remitido a ese establecimiento sin identificarse en el día de la fecha a los efectos de que lo vele la familia y mañana a la hora [ilegible] será devuelto para que se le practique la autopsia.

15 Al día siguiente, el comisario enviaba una nueva nota al director de la Morgue informando que remitía

(...) para ser autopsiado, el cadáver de JOSÉ OLIVEIRA, español, de 69 años de edad, con 45 de residencia, casado, panadero, alfabeto y se domiciliaba en Amenábar 3229, que el 12 del corriente a las 19 y 40, falleció a consecuencia de haber sido embestido (...) por el automóvil colectivo chapa № 15.791, línea 57, conducido por Santos Yuri 
(...) La víctima pertenecía a la raza blanca, profesaba la Religión Católica, nació en España, provincia de Pontevedra, pueblo de Padrón, el 4 de abril de 1870, y era casado con María Esclavitud Luna, de cuya unión nacieron cuatro hijos que aún viven, y son: José, de 30 años; Dolores, de 35 años; María Elena, de 33 años y Juan, de 29 años de edad.

\section{enterrado, originalmente, en el cementerio del Oeste (Chacarita) para luego ser} trasladado al cementerio de San Fernando, una vez que la familia pudo comprar una parcela. Pero lo que nunca se había contado en la familia Oliveira es que mi bisabuelo había pasado por la Morgue Judicial y, mucho menos, que su rostro había sido reproducido en una máscara mortuoria que se encontraba en exhibición en el Museo Forense.

Pero no fue allí que terminó mi asombro. Con el expediente en mano y gracias a los datos que mi guía tenía aparte, pude saber que durante un tiempo la vértebra cervical cuya quebradura le había provocado la muerte a mi antepasado había estado en exposición en el Museo, para luego ser enviada al depósito. El funcionario que tan amablemente y -por qué no decirlo- con muchísimo entusiasmo me ayudó a encontrar el expediente, se ofreció, también, a buscar la cervical para que la pudiese ver. Mi respuesta al ofrecimiento fue negativa. Con los registros burocráticos, para mí era suficiente.

Con una copia del expediente en mano, una excitación inmensa y el recuerdo de la vértebra archivada, terminé mi visita, devenida en descubrimiento, al Museo de la Morgue. Inmediatamente me dirigí a un teléfono público y llamé a mi madre y a mi tía para contarles mi "aventura familiar" y comenzar a contrastar las versiones de los pocos recuerdos familiares con los registros documentales.

\section{Recuerdos de familia}

Mi tía tenía tres años cuando había muerto su abuelo -mi madre aún no había nacidoy recordaba que en la familia se tenía la sospecha de que el accidente se había producido "porque estaba borracho cuando cruzó la avenida. Era muy trabajador, pero le gustaba el trago. Era muy duro el trabajo de panadero: levantarse al alba, trabajar a temperaturas altísimas..."

20 Ante el comentario sobre los gustos etílicos de mi bisabuelo, recordé en ese momento que en el expediente había un formulario en el que se indicaba que se había mandado hacer un análisis para ver si existía alcohol en sangre. Sin embargo, después de esa nota, nada acreditaba que hubiese estado alcoholizado o no. Solo una pequeña noticia extraída del diario La Nación del 13 de septiembre, hacía referencia a la actitud "sorprendente" de la víctima: “(...) que se hallaba detrás de un camión allí estacionado y que no pudo ver aquel vehículo [colectivo], se lanzó corriendo para atravesar la calzada".

21 Por su parte, mi madre discutía la idea de que fuese católico, tal como aparecía en el expediente:

-¡Imposible! Era anarquista. ¡No podía ser católico! Él es el que le enseñó a tu abuelo que los nombres con los que conocemos a las facturas (bolas de fraile, suspiros de monja, vigilantes, cañoncitos, sacramentos) eran nombres para burlarse de la Iglesia, del Ejército y de la Policía... 
A lo cual, mi tía le respondía que él decía que era católico pero que no era practicante; la católica-practicante era la abuela María Esclavitud -su esposa-, por eso todos los hijos estaban bautizados. Dirigiéndose a mí, me dijo: “-Cuando tu abuelo nació, casi se muere a los pocos días y ambos estuvieron de acuerdo en darle las aguas del socorro". ${ }^{1}$

Pero más allá de las distintas versiones que podían advertirse entre los recuerdos familiares y los documentos judiciales, y de las discrepancias de sus nietas en torno a sus gustos, vicios y creencias, lo cierto es que si en algo acordaban era que en la familia nunca se había mencionado que el cuerpo de José oliveira hubiese pasado por la Morgue Judicial.

\section{Algunas preguntas y líneas de fuga}

\section{Según la página web del Centro de Información Judicial (CIJ)}

(...) la mayor parte de los restos humanos [del Museo Forense] pertenece a personas fallecidas entre las décadas de 1930 y 1940, víctimas de accidentes, homicidios o suicidios, cuyos cadáveres en su momento no fueron reclamados ni retirados y se destinaron a fines de investigación. ${ }^{2}$

Tanto el expediente como los relatos de sus nietas muestran que el cadáver de mi bisabuelo no solo fue reclamado, sino retirado de la Morgue por mi abuelo para ser velado por sus familiares, devuelto al día siguiente para que se le practicase la autopsia en la Morgue y vuelto a entregar a los deudos para que llevaran a cabo su inhumación. Definitivamente, no se trataba de un cadáver "no reclamado". Por otra parte, al devolver el cuerpo a la familia -sin que esta lo supiera-, una pequeña parte de él -su vértebra cervical- había quedado en la Morgue con fines de investigación. Nadie de la familia sabía esto; sesenta y seis años más tarde -gracias a un funcionario orgulloso y celoso de su trabajo- pudimos enterarnos de esa apropiación.

Cuando advertí este hecho, inmediatamente vino a mi memoria el caso de "los amotinados de Tyburn" y el robo de cadáveres, desarrollado por Edward Thompson (1989). En su análisis, el historiador británico sostenía que dichas prácticas debían ser vistas antes que como supersticiones y despojos de antiguos modelos de pensamiento, como nociones diferentes de respeto sobre la integridad de los cadáveres, los rituales de enterramiento y determinadas creencias sobre la muerte y cómo tratarla. Pero para el autor, las revueltas implicaban también la amenaza a un tabú: "en el caso de la disección de cadáveres o el colgar cadáveres con cadenas, una clase está deliberadamente, y como acto de terror, rompiendo o explotando los tabúes de otra" (Thompson, 1989, p. 50).

27 Si bien en el caso de mi familia no hubo ningún tipo de amotinamiento, ni siquiera queja -básicamente porque lo que primó fue el desconocimiento-, el recuerdo del caso inglés llevó a preguntarme sobre quiénes estaban destinados a la exposición pública en "nombre de la ciencia" en un museo como éste, que desde sus orígenes ha sido objeto de disputa entre la medicina y la justicia penal. $Y$ en este sentido, comienzo a entrever que los cuerpos que son víctimas de las fuerzas de seguridad, de las agencias penales y de la ciencia médica, son también aquellos que pueden mostrarse, exhibirse y sobre los que se puede disponer, tanto en vida como después de muertos.

Es innegable que la exposición de restos mortales "auténticos" en frascos acomodados en vitrinas impacte, si no de un modo morboso, azuzando la curiosidad del espectador 
que se encuentra en un lugar cuyo sostén y justificación es la existencia, por detrás de esos tejidos anatómicos, de todo un saber médico-legal y policial. Sin embargo, en este caso, no fueron esos restos humanos descarnados en su visualización -que podrían aparecer como el epítome de la violencia- los que me invitaron a escribir. Por el contrario, las cabezas en los frascos eclipsaban las máscaras mortuorias de los trabajadores y, por lo tanto, esa violencia que ejerce la medicina y las burocracias judiciales y policiales con ciertos cuerpos y poblaciones particulares. En este sentido, no fue lo "morboso" lo más violento ni mi "principio de la búsqueda" (Sirimarco, 2016, p. 17) sino lo "insípido", aquello que tapaba las violencias más cotidianas, opacas y repetidas que se ejercían sobre determinados cuerpos.

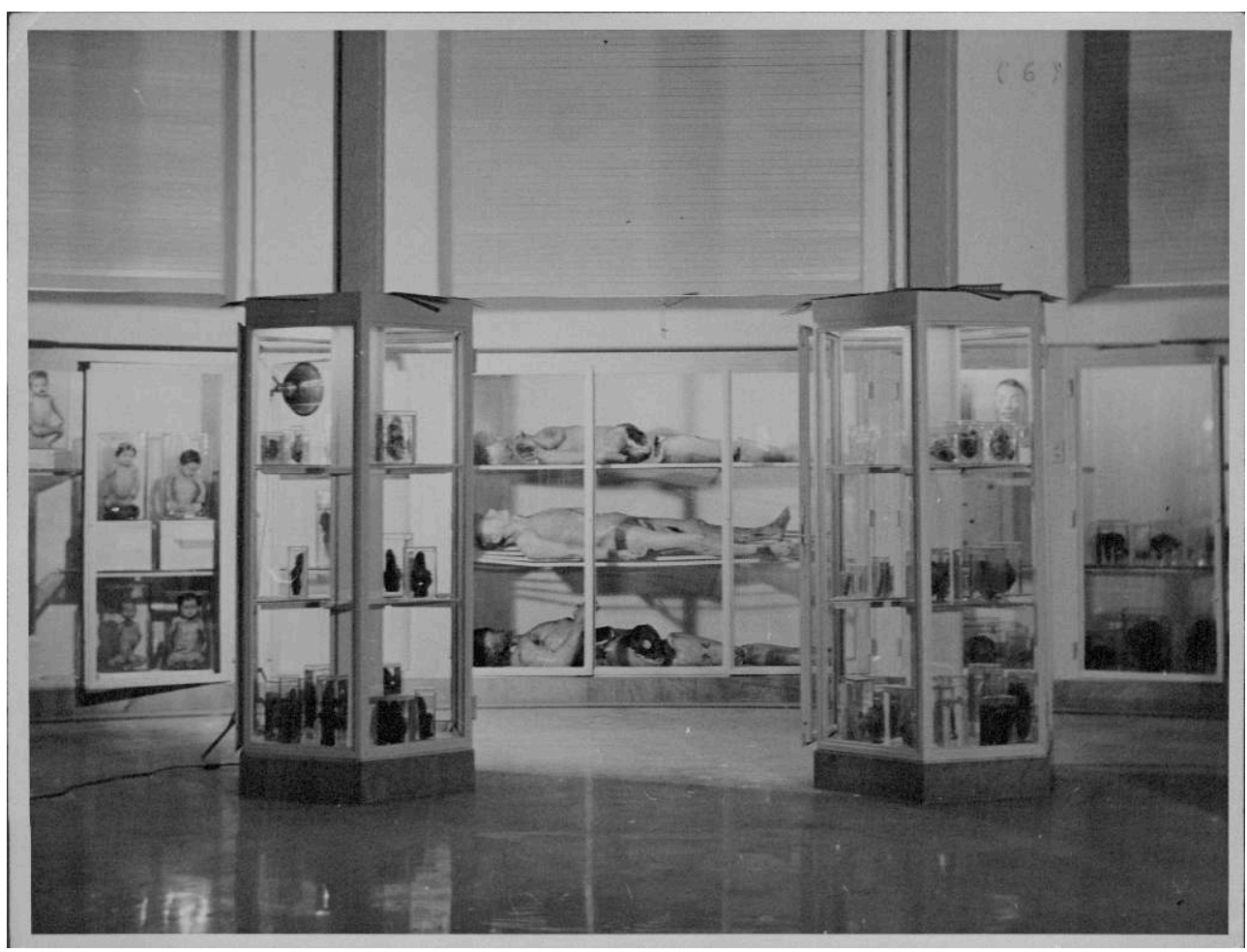

Imagen 3: Museo Forense. Archivo General de la Nación. Inventario 88794

Asimismo, la figura de mi bisabuelo como estereotipo de trabajador, pobre e inmigrante -y la de todas las otras máscaras mortuorias que lo acompañaban- se contrapone a la imagen del policía heroico de los museos de las fuerzas de seguridad (Sirimarco, 2016) e inclusive a la de los propios delincuentes del Museo Forense, con prontuarios frondosos e historias dignas de una novela. Hasta la representación misma del trabajador es opaca y poco llamativa; lo que debe brillar ahí es la ciencia que le dio ese lugar arriba de las vitrinas. Sin embargo, en esas historias grises se puede entrever el accionar mismo del sistema penal y de la violencia sobre esos cuerpos muertos que, una vez ingresados, le pertenecen.

Decía en párrafos anteriores que, si el cadáver ingresó, el registro burocrático de ese ingreso tiene que estar. En otras palabras, tras todo cuerpo existe un expediente que lo sostiene, que legitima su existencia. $Y$ en este sentido, es posible pensar en las burocracias que sostienen y guardan objetos, cervicales, tatuajes, así como también en los burócratas que las habitan. Sus perfiles transitan un abanico que va desde el empleado desinteresado e indolente hasta el convencido guardián que se apropia y defiende "sus" objetos y expedientes, decidiendo quién podrá verlos y quién no. El "hallazgo" del 
expediente familiar y del burócrata que me lo facilitó, muestran esa articulación entre funcionarios y burocracias que dejan huella de su accionar, por horroroso $-\mathrm{o}$ anodino - que este sea.

31 El expediente de mi bisabuelo cuenta una versión sobre la historia de su muerte, de su máscara mortuoria y de su "cervical de exposición". El relato familiar cuenta otra versión, con similitudes, diferencias y desconocimientos/ocultamientos. Se necesita entretejer, y contrastar estos distintos relatos para reconstruir la historia de esa muerte y de ese cuerpo y comprender las lógicas de funcionamiento de las burocracias -policiales, judiciales, médicas y administrativas- que la capturaron.

\section{BIBLIOGRAPHY}

Sirimarco, M. (2016). El último Chonino: Crónica de una investigación sobre policía y heroísmo. Buenos Aires: Antropofagia.

Thompson, E. P. (1989). Tradición, revuelta y consciencia de clase. Estudios sobre la crisis de la sociedad preindustrial. Barcelona: Editorial Crítica.

\section{NOTES}

1. Ritual cristiano que se realizaba como una suerte de "bautismo de emergencia" cuando se creía que el recién nacido corría peligro inminente de muerte. Lo podía hacer cualquier persona comenzando con la fórmula: "yo te bautizo, en el nombre del padre...”.

2. https://www.cij.gov.ar/nota-33457-Museo-Forense--un-espacio-de-inter-s-jur-dico-y-cientfico.html

\section{AUTHOR}

\section{MARÍA JOSÉ SARRABAYROUSE OLIVEIRA}

Facultad de Filosofía y Letras, Universidad de Buenos Aires y Consejo Nacional de Investigaciones Científicas y Técnicas, Argentina.

Correo electrónico: mariajosesarra@gmail.com 